\title{
FAIR Research Data
}

Volker Mehrmann (TU Berlin, Germany), President of the EMS

In many European countries, e.g. Germany, there is a strong movement for all research data to be freely available according to the FAIR principles (findable, accessible, interoperable and reusable). See https://libereurope. eu/wp-content/uploads/2017/12/LIBER-FAIR-Data.pdf

This is a major challenge for scientists who produce massive data, e.g. from numerical simulations, but also for mathematical research as a whole.

How and in which form can we standardise the way to find mathematical formulas or mathematical theorems, when different communities adopt other terminology for the same objects while using the same formulas for different objects?

The German Science foundation DFG has just started a large call for building research data infrastructures to deal with this, see e.g. https://www.dfg.de/en/service/ press/press_releases/2018/press_release_no_58/index. html

Most people in the mathematical community seem to ignore these developments, but this may lead to real threats for the community if we do not join the movement right from the beginning.
Examples of such threats could be that standards are fixed which are incompatible with our current way of producing mathematical articles in LATEX and PDF, or that formulas are only stored graphically. Another problem may be that standards for model generation, mathematical software or simulation data are not to our taste. It is clear that commercial code providers are heavily lobbying governments to set standards that suit their particular needs, and that IT companies and data analytics people have their own views of how data should be addressed.

The mathematical community must unite in a common quest to be on board right away with the developments (the German maths community has already decided to do this and is participating in a joint consortium proposal), to make these principles realistic for mathematics and the neighbouring sciences and to preserve and improve established publishing standards to be able to deal with future developments. This may also require the construction of new and uniform concepts, such as semantic annotation of formulas or theorems. 